\title{
Advancing precision public health using human genomics: examples from the field and future research opportunities
}

\author{
Megan C. Roberts ${ }^{1}$, Alison E. Fohner ${ }^{2}$, Latrice Landry ${ }^{3}$, Dana Lee Olstad ${ }^{4}$, Amelia K. Smit ${ }^{5}$, Erin Turbitt ${ }^{6}$ and \\ Caitlin G. Allen ${ }^{7^{*}}$ (D)
}

\begin{abstract}
Precision public health is a relatively new field that integrates components of precision medicine, such as human genomics research, with public health concepts to help improve population health. Despite interest in advancing precision public health initiatives using human genomics research, current and future opportunities in this emerging field remain largely undescribed. To that end, we provide examples of promising opportunities and current applications of genomics research within precision public health and outline future directions within five major domains of public health: biostatistics, environmental health, epidemiology, health policy and health services, and social and behavioral science. To further extend applications of genomics within precision public health research, three key cross-cutting challenges will need to be addressed: developing policies that implement precision public health initiatives at multiple levels, improving data integration and developing more rigorous methodologies, and incorporating initiatives that address health equity. Realizing the potential to better integrate human genomics within precision public health will require transdisciplinary efforts that leverage the strengths of both precision medicine and public health.
\end{abstract}

Keywords: Precision medicine, Public health, Precision public health, Transdisciplinary research, Human genomics research

\section{Background}

Precision medicine promises to revolutionize health by incorporating individual-level characteristics (genetic, lifestyle, environmental factors) into medical treatment and prevention strategies to provide "the right care to the right individual at the right time" [1]. This approach allows for the application of individually tailored preventive or therapeutic medical interventions that may be more effective than "one size fits all" approaches, thereby improving quality of care and reducing unnecessary diagnostic testing and therapies. It has been debated whether precision-based approaches should be applied

\footnotetext{
* Correspondence: calle27@emory.edu

${ }^{7}$ Department of Behavioral Social and Health Education Sciences, Rollins School of Public Health, Emory University, 1518 Clifton Road, Atlanta, GA 30322, USA

Full list of author information is available at the end of the article
}

not only to individual-level clinical care, but also to efforts to improve health at a population level, i.e., precision public health [2-4]. While the relative merits of targeted versus universal approaches to disease prevention, treatment, and control at the population level remain the subject of debate, there is an increasing recognition that more precise interventions can advance health at a population level [5].

Precision public health is an approach that integrates precision and population-based strategies to provide "the right intervention to the right population at the right time" [6]. This can include the scaling of precision medicine initiatives and the translation of basic-science discoveries to the population level. A key aspect of precision public health lies in its potential to develop more accurate methods to identify multi-level risk factors and their impact on population health and to use this information to 
develop targeted policies and programs to promote health [7]. While other -omics approaches (e.g., transcriptomics, proteomics, and metabolomics) are certainly relevant to precision public health, incorporation of human genomics into precision public health initiatives is particularly promising given evidence of substantial heritability of chronic diseases including obesity, cardiovascular disease, and cancer, which are among the major public health challenges of the twenty-first century $[8,9]$. Thus, the use of human genomics in precision public health can improve measurement of individual-level factors that shape health, serving as a conduit between precision medicine and public health for improving health across individuals and populations $[7,10]$.

To date, integrating human genomics research within precision public health initiatives has supported more precise disease prevention and control strategies, including newborn screening and risk-stratified prevention (e.g., enhanced cancer screening for individuals with pathogenic BRCA1/2 variants) [11-13]. However, currently, application of human genomic research to the translation of precision public health has been relatively limited [14, 15]. Each of the major domains of public health-biostatistics, environmental health, epidemiology, health policy and services, and social and behavioral health-offers complementary opportunities to improve precision public health applications through human genomics [16]. Here, we describe examples of initiatives that integrate human genomics within precision public health research, as well as opportunities to advance research in each of these public health domains. Finally, we discuss challenges and opportunities to integrating human genomics within the field of precision public health that cut across the five major public health domains.

\section{Examples of integrating human genomics research and public health}

We describe ways by which the five domains of public health endorsed by the Association of Schools and Programs of Public Health have integrated consideration of human genomics within precision public health research. The five domains include as follows: biostatistics, environmental health, epidemiology, health policy and health services research, and social and behavioral health (Table 1) [16].

Biostatistics involves the study of theories and techniques for collecting, analyzing, and interpreting quantitative data relevant to public health [16]. The immense size and scale of the datasets used in precision public health research necessitate advanced statistical methods with enhanced approaches for reducing noise and enhancing signal detection. These datasets often include multidimensional genetic biomarker data from large numbers of subjects with serial measures repeated over time [28]. Indeed, current genomic technologies allow for the entire human genome to be sequenced through whole genome sequencing. Results from the $1000 \mathrm{Ge}-$ nomes Project suggest that a typical human genome differs from the reference at 4.1 to 5 million sites [17]. In addition to these genomic biomarkers, the ability to detect other biomarkers including the transcriptome, proteome, and metabolome is also increasing significantly. Taken together, the scale of the individual biomarker data that is critical to advancing precision public health, in addition to the complexity of modeling biologic, behavioral, and environmental factors, is mathematically challenging. Thus, the development of advanced statistical methods that allow estimation of interactions between individual-level (e.g., genetic, behavioral factors) and macro-level factors (e.g., environmental exposures and policies) and to identify latent relationships using artificial intelligence (AI) will be necessary.

One example of existing precision public health initiatives within the biostatistics domain of public health is the Genetic Analysis Workshop [18]. This is a collaboration of genetic epidemiologists and statisticians who evaluate and compare statistical genetic methods for multi-omics data including evaluations of causal modeling for multi-omics data and of quality control of highthroughput methylation data for epigenetics studies. These efforts to improve data and modeling quality may help to optimize algorithms for decision support in disease prevention and treatment contexts. Specific examples of this can already be seen for genomics with the ASK2ME (All Syndromes Known to Man Evaluator), which calculates risk of cancers associated with gene variants using data from published studies [19]. Further development of these types of methods and integration with technology, such as the development of algorithms for decision support tools and data resources using AI, can improve risk-stratified cancer prevention and control efforts which are critical to advancing precision public health.

Environmental health focuses on the interplay between individuals and their environment to promote health. The field of environmental health has long noted that individual-level factors, such as genetics, interact with macro-level environmental factors to impact population health. The integration of human genomic research within environmental health research may help to elucidate how individual-level factors (e.g., -omics data) and macro-level factors interact to influence health, providing a better understanding of mechanisms underlying complex gene-environment interactions. Understanding how the "exposome" impacts disease development and progression will allow precision public health researchers to target and refine interventions for populations at high 
Table 1 Illustrative examples of study domains proposed for human genomics research in precision public health

\begin{tabular}{|c|c|c|c|}
\hline $\begin{array}{l}\text { Study domain and } \\
\text { definition }\end{array}$ & Promising opportunities & $\begin{array}{l}\text { Specific examples of } \\
\text { application in precision } \\
\text { public health }\end{array}$ & Possible future directions \\
\hline
\end{tabular}

\section{Cross-cutting \\ considerations in health policy, data integration, and health equity}

Biostatistics: Study of theories and techniques for collecting, analyzing, and interpreting quantitative data relevant to public health issues.

\section{Allow for development of} new methods for interrogating complexity of precision public health data
High-throughput genomics to provide more precise modeling and higher resolution of statistical interactions in relation to common or multifactoria complex diseases (e.g., Genomes Project, Genetic Analysis Workshop, ASK2ME) [17].

\section{Environmental Health:}

Study of assessment, control, and prevention of factors in the environment that can adversely affect the health of present and future generations.
Elucidate how individual and macro-level factors interact to influence health
Parkinson's Genes and Environment Study collected mobile health technology for both environmental and personal health information to assess link between pesticide exposure and Parkinson's disease $[20,21]$.
Epidemiology: Application of the scientific method to the study of disease in populations for the purpose of prevention and control.
Health Policy and Services Research: Research on the cost, access, and quality of the health care system, and on policy issues affecting the organization, financing, and delivery of health care services.
Improve knowledge of multi-level risk factors to enhance risk assessment and enable risk-stratified screening, treatment, and surveillance
Understanding economic and health impact, as well as health equity of precision public health approaches

Development of algorithms for decision support tools and data resources using $A$ for enhanced resolution and interpretation of multi-omics datasets

- Data Integration:

addressing data storage and security issues, data integrity, data integration with variables across levels; methods for data analysis.

- Health Equity: developing novel methods to examine how dimensions of disadvantage interact to create health risks in more precisely defined marginalized subgroups of the population (i.e., according to multiple indicators of social position)

\section{- Health Policy:} harmonizing health policies across international and community boundaries to ensure uptake of environmental initiatives that support precision public health.

- Health Equity: conduct subgroup analyses to examine how different dimensions of social position interact to shape vulnerability to environmental risk factors for poor health.

Risk-stratified screening approaches that incorporate genetic risk to improve costeffectiveness, reduce over diagnosis and maintain the benefits of screening for those at highest risk of breast cancer.

Partnering with populations historically absent from biomedical research to improve diversity and equity of epidemiological knowledge (NorthwestAlaska Pharmacogenetics Research Network) [22]

Implementing Genomics in Practice Consortium; understanding barriers to implementation of cascade screening for hereditary cancer conditions, such as Lynch syndrome [23].
Advancement of our understanding of multi-level risk factors for targeting prevention and screening strategies to populations at highest risk

\section{- Data Integration:} supporting data sovereignty.

- Health Equity: ensuring data are collected from diverse, representative groups.
Evaluation of clinical utility, cost-effectiveness, and patient-reported outcomes

\footnotetext{
- Health Policy: ensuring privacy of potentially highly identifiable information. Considerations of when and how to intervene on genetic information.

- Data Integration: incorporating genetic test results into electronic health records.

- Health Equity: integrate consideration of the social determinants of health within health care (e.g. social prescribing).
} 
Table 1 Illustrative examples of study domains proposed for human genomics research in precision public health (Continued)

\begin{tabular}{|c|c|c|c|c|}
\hline $\begin{array}{l}\text { Study domain and } \\
\text { definition }\end{array}$ & Promising opportunities & $\begin{array}{l}\text { Specific examples of } \\
\text { application in precision } \\
\text { public health }\end{array}$ & Possible future directions & $\begin{array}{l}\text { Cross-cutting } \\
\text { considerations in health } \\
\text { policy, data integration, } \\
\text { and health equity }\end{array}$ \\
\hline $\begin{array}{l}\text { Social and Behavioral } \\
\text { Science: Interdisciplinary } \\
\text { study focusing on how } \\
\text { health education can affect } \\
\text { behavior and lifestyle } \\
\text { decisions that have an } \\
\text { impact on public health. }\end{array}$ & $\begin{array}{l}\text { Translate genomics } \\
\text { applications for } \\
\text { population health and } \\
\text { community-based human } \\
\text { genomic research }\end{array}$ & $\begin{array}{l}\text { Assess individuals' } \\
\text { preferences to learn } \\
\text { genomic information, assess } \\
\text { family-based interventions, } \\
\text { implementation of screening } \\
\text { approaches, and assess how } \\
\text { social environmental inform } \\
\text { understanding of gene- } \\
\text { environment associations. } \\
\text { Efforts in ethical, legal, and } \\
\text { societal implications (ELSI) of } \\
\text { human genomics research } \\
\text { [24], NCGENES2 [25], and } \\
\text { CARTaGENE project [26, 27]. }\end{array}$ & $\begin{array}{l}\text { Public understanding of } \\
\text { precision public health, } \\
\text { genetic and genomic risk } \\
\text { communication, adequate } \\
\text { reach of precision public } \\
\text { health interventions, } \\
\text { precision public health } \\
\text { intervention development } \\
\text { and testing of interventions } \\
\text { to promote behavior } \\
\text { change, and new behavioral } \\
\text { targets that may be } \\
\text { informed by precision-based } \\
\text { approaches }\end{array}$ & $\begin{array}{l}\text { - Health Policy: Supporting } \\
\text { implementation of cascade } \\
\text { screening; ethical } \\
\text { implementation of new } \\
\text { human genomics } \\
\text { discoveries. } \\
\text { - Health Equity: conduct } \\
\text { subgroup analyses to } \\
\text { examine how different } \\
\text { dimensions of social } \\
\text { position interact to shape } \\
\text { vulnerability to behavioral } \\
\text { risk factors for poor health. }\end{array}$ \\
\hline
\end{tabular}

risk of poor health outcomes. For example, a geneenvironment interaction study using international cohort data assessed whether the association between trafficrelated air pollution exposure and incident childhood asthma was associated with genetic factors. Results identified an interaction with air pollution for three singlenucleotide polymorphisms, suggesting that geneenvironment interactions may be associated with asthma development [29]. Individuals with these known polymorphisms could be advised to limit time spent outdoors on days where air pollution is particularly high, a development that is already underway within smart cityenabled built environment initiatives [30]. Other work has identified potential gene-environment interactions between workplace exposures to asbestos and family history of mesothelioma [31]; given increased risk of hazardous workplace exposures among underserved populations, this may have implications for our understanding of and interventions related to reducing socioeconomic disparities in health outcomes [32]. In another example, investigators from the Parkinson's Genes and Environment Study collected mobile health technology data, as well as environmental, genetic, and personal health information longitudinally in order to better understand the link between pesticide exposure, genetics, and Parkinson's disease [20, 21]. Future work to understand mechanisms behind complex environmental exposures and their interactions with individuallevel factors may lead to environmental interventions that target populations at high risk of adverse outcomes [33, 34].

Epidemiology uses analytic methods to assess patterns and causes of health states in populations, which encompass individual-level characteristics (e.g., genetics) as well as macro-level factors (e.g., neighborhood and community characteristics). Precision public health draws on epidemiological methods such as population-level surveillance to improve knowledge of multi-level health risk factors which can inform risk-stratified screening, treatment, and prevention interventions. Given advances in human genomic technologies, it is anticipated that genomic information (along with other individual risk factors) will be incorporated into precision public health strategies [33, 35, 36]. These strategies, informed by genetic epidemiological studies, will be critical to promoting positive health-related practices [37, 38], risk-stratified screening and treatment, reducing overdiagnosis, and developing more personalized interventions [39-41]. To this end, examples of human genomics research in epidemiology include investigating associations between multiple common gene variants with disease risk [35, 42, 43], the relationship between genomic (polygenic) variants and monogenic variants [44], the contribution of common variants to risk prediction models along with other risk factors (potentially including other genetic risk information, such as higher penetrance single genes) [45, 46], the role of genetics in identifying rare diseases in newborn screening [4], the epigenome [47, 48], and the interplay between biomarkers and drug response across diverse communities [49-51]. For example, the Northwest-Alaska Pharmacogenetics Research Network is partnering with American Indian and Alaska Native communities to identify known and novel genetic variants associated with drug response and health status in their communities (vitamin D levels, vitamin $\mathrm{K}$ nutrition sources, and metabolism related to blood clotting) [22]. Including racially/ethnically diverse populations in human genomic research, such as this one, will contribute to a more generalizable evidence base to improve equity of resulting precision public health interventions [22]. In addition to understanding drug response, evidence from another study that incorporated genetic information into a risk prediction algorithm suggests that some women may benefit from earlier than recommended breast 
cancer screening, while other women may not be harmed by delaying the start of routine screening [52]. Continued research examining genetic interactions with contextual-level factors will inform more precise prevention and screening which target those who stand to benefit the most from these strategies [53].

Health policy and health services research examines quality, cost, and access to health care among the population. These data are essential to understand the economic and health impact of precision public health initiatives, including whether they support health equity. With the evolution of genomic testing in both treatment and prevention settings, health services research will be key in the evaluation of clinical utility, cost-effectiveness, and patient-reported outcomes. These data will be essential in building the evidence base needed for policymakers and practitioners alike to translate human genomic research in precision public health to benefit populations. In particular, the field of implementation science has the potential to play a pivotal role in leveraging precision medicine to benefit population health and to promote health equity (i.e., enabling precision public health) [54-56]. Implementation science is the study of strategies to adopt and integrate evidence-based health interventions such as those generated within the field of genomic medicine into clinical and community settings to improve individual outcomes and benefit population health [57]. Currently, the Implementing Genomic in Practice Consortium [23], funded by the National Human Genome Research Institute, is seeking to enhance the use of genomic medicine in part by integrating implementation science frameworks into delivery of precision medicine. These efforts have resulted in the development of implementation guides for health care systems, clinics, and provider champions who are interested in implementing pharmacogenomics testing [58, 59]. More specifically, the Consortium has developed guidance for implementing and maintaining CYP2D6 testing to guide opioid prescribing as well as CYP2C19 testing for clopidogrel prescription [58]. Across the world, implementation science is at the forefront of human genomics programs and precision public health initiatives, a further example being the Australian Genomics Health Alliance. This national partnership aims to assess the integration of human genomics into the public healthcare system, using implementation science to guide and evaluate the various efforts across more than 80 organizations [60]. Research by this Alliance studying the implementation of ultra-rapid exome sequencing in the neonatal or pediatric intensive care setting has highlighted the complexity of healthcare systems and the necessity of adapting to local context, fostering participatory culture, collective learning, and distributed leadership [61].
Social and behavioral research studies ways that behaviors and the conditions of daily life (i.e., the social determinants of health) shape health across the life course [62]. Historically, social and behavioral research related to precision public health has focused on ethical, legal, and social implications (ELSI) of human genomics research [24]. Given the more traditional understanding of genetics as being familial, social and behavioral research has contributed to understanding the ELSI of sharing genetic information with family members by exploring concepts such as autonomy and beneficence. Numerous calls have also been made for social and behavioral researchers to go beyond impacting human genomics research by integrating human genomics considerations within precision public health initiatives $[63,64]$. Examples of current and future precision public health research opportunities in the social and behavioral sciences include: improving public understanding of genomics and data sharing, genetic and genomic risk communication, expanding the reach of precision public health interventions, developing and testing precision public health interventions to promote behavior change, and identifying new and/or more precise behavioral targets that may be informed by precision public health approaches [65]. Research in this area promises to improve public trust and willingness to participate in interventions that address their genetic risks.

To date, social and behavioral scientists have made progress in translating genomic applications for the benefit of population health by using community-based genomic research that includes communities as partners in human genomic research $[53,66]$. For example, the North Carolina Clinical Genomic Evaluation by Nextgeneration Exome Sequencing 2 (NCGENES2), a diagnostic genomic sequencing study for children with undiagnosed conditions, explored the impact of a Community Consult Team consisting of clinicians and caregivers in order to maximize the utility and equity of genomic sequencing [25]. Engaging this team resulted in adaptations to the study protocol and materials, demonstrating the valuable contribution of community engagement to inform the implementation of translational human genomics research [67]. Another example, the Quebec CARTaGENE project, a large-scale genetic database that serves as a public research platform, engaged the public about their willingness to participate in such a project. The first public engagement highlighted the importance of transparency, maintaining confidentiality, and ensuring the ability for donors to provide feedback and guidance. Further, the team found a need to tailor and target communication about the project across patient populations $[26,27]$. Other related research has incorporated the patient voice by assessing patient and family preferences for learning genomics information in 
order to inform family-based interventions that aim to disseminate genetic information to families at high risk of disease [68-72].

\section{Cross-cutting challenges and opportunities for integrating human genomics research within precision public health}

As demonstrated by examples from the field, principles of precision public health are being applied by researchers working at the intersections of precision medicine, genomics, and public health. In addition to domain-specific advances, innovations cutting across all domains are needed to advance precision public health initiatives, including (1) revised health policies, (2) improved data integration and development of more rigorous methodologies, and (3) an emphasis on health equity (Table 1) [73-75].

Health policies at all levels including clinic, industry, health system, state, and federal will need to adapt to rapidly growing precision-based approaches in order to support the goals of precision public health.

The development of new policies focused on ensuring the privacy, confidentiality, and regulation of genetic results delivered to individuals will be important as precision public health becomes more established due to the potential for precision health data to be highly identifiable. Further, as our ability to predict public health outcomes improves, we must consider when and how to intervene and the ethical and legal ramifications of action or inaction. For example, researchers have identified a link between child abuse and antisocial behavior with a common monoamine oxidase (MAOA) gene variant [76]. A meta-analysis of 27 studies identified a robust association between increased likelihood of antisocial outcomes after childhood adversity among carriers of the low-activity MAOA genotype. Definitions of childhood adversity and antisocial behavior varied, with the strongest association with childhood maltreatment. However, an intervention based on these data, presumably to reduce child abuse, should be a universal goal and not targeted towards a specific subpopulation with low-activity MAOA genotype. With each new epidemiological association, policymakers must decide whether and how the results should be used to advance precision public health. Policies that are proactive in addressing the changing landscape will be essential, as rapid advances in precision public health become available. Experience with ELSI could help inform decision making about these new discoveries and how they can be ethically implemented and translated into new policies. Specifically, there are a number of Centers of Excellence in ELSI Research (CEER) funded by the National Human Genome Research Institute. These projects use interdisciplinary approaches to address complex and rapidly emerging ethical, legal, and societal issues that occur as research advances in genomics [77].

In addition, certain limitations in current policies must be addressed. For example, in the USA, the Genetic Information Non-Discrimination Act fails to protect the public from life insurance discrimination based on preexisting genetic conditions, most greatly impacting socioeconomically vulnerable citizens who may not be able to afford life insurance rates that are raised due to their genetic risks [78]. Conversely, US state-level genetic privacy laws may inhibit the sharing of important genetic information with relatives, and while this may be important in protecting genetic privacy, it may also complicate precision public health efforts to implement cascade screening (or family genetic testing) to identify and manage disease risk among individuals with highly penetrant genetic conditions [79]. Future research studying the impact of current policies, as well as barriers and facilitators to enacting these policies, will be essential for building a policy landscape that facilitates precision public health.

Improved data integration and methods will be necessary to leverage the complexity of human genomics data for addressing precision public health problems. Incorporating these data with other individual-, interpersonal-, community-, and environmental-level data in a meaningful and rigorous way will require novel methods for data measurement, collection, management, and integration [73]. In particular, advanced informatics is needed to fulfill the opportunities and meet the challenges of integrating human genomic research within precision public health through information technology infrastructure development [74]. As the underpinnings of multi-level mechanisms take shape, multi-level systems-based interventions will be necessary. These include study designs and data storage infrastructure that allow researchers to understand both the synergistic and independent effects of these complex problems and multi-level solutions across diverse populations. Future opportunities in this area include improving complex study designs and big data management and storage. In addition, researchers will need secure data systems that allow data to be shared efficiently and ethically between researchers and public health agencies and practitioners. Further, data integration of genomic and other precision public health data into the electronic health record with appropriate decision support will be important in integrating these data into the clinical setting to improve health $[75,80,81]$.

One application of improved data integration and related methods to help address precision public health problems is through the use of conditional random forests (a machine learning approach). Nau et al. used this approach to identify features of social, food, and physical activity environments that jointly predicted whether a 
community's environment could be considered as primarily obesogenic or obesoprotective [82]. The authors used a dichotomous indicator of average BMI $z$-score among children living in each community as a proxy for each of these outcomes. Of the 44 community characteristics examined, a combination of 13 features of the social, food, and physical activity environment correctly classified two-thirds of communities as obesogenic or obesoprotective, with social features being the most informative in this respect. This study offers a way forward in use of large datasets to help define more precise targets for public health intervention, which are critical to precision public health initiatives.

Health equity, or fair access to resources that allow for an individual to reach their full health potential, is integral to the future of precision public health. Broadly, ensuring health equity requires that individuals have access to appropriate resources regardless of their social position or circumstances. As it relates to precision public health, Olstad and McIntyre specifically define "precision public health" as "the study of how multiple dimensions of social position interact to confer health risk differently for precisely defined population subgroups according to the social contexts in which they are embedded, while considering relevant biological and behavioral factors" [7]. Enhancing attention to health equity is perhaps the most important opportunity for the intersection of precision- and population-based approaches if we are to ensure that precision public health retains its focus on improving health for all members of society, and the health of marginalized groups in particular [53, 83].

Unfortunately, racial, ethnic, and socioeconomic disparities in access to precision approaches, including genetic testing, have already emerged [84, 85]. For example , underrepresentation of racial and ethnic minority populations in genomic databases limits the benefit of newly developed tools for assessing risk, prognosis, and therapeutic response for patients who already experience limited access to and poorer quality of healthcare due to factors such as poverty and systemic racism [86]. Specific efforts have been taken to implement genomic screening for hereditary breast and ovarian cancer syndrome (HBOC), Lynch syndrome (LS), and familial hypercholesterolemia $(\mathrm{FH})$ among diverse populations (i.e., non-European ancestry populations) that are commonly excluded in genomic medicine research [87]. Most participants in this diverse sample opted for the return of results, with younger participants, female participants, and Hispanic/Latinx participants being most likely to opt to receive their results [88].

Community engagement, a cornerstone of public health research, may facilitate the implementation of precision public health initiatives seeking to promote health equity [10]. Indeed, initiatives such as the All of
Us Research Program have recognized a need to restore trust among underserved and historically marginalized groups, such as Black, LatinX, and Indigenous American groups, to participate in health research through community engagement principles $[89,90]$. Thus, it is critical to ensure that equity remains a core concern within precision public health initiatives [91]. With its emphasis on health equity and incorporating multiple levels of influence on population health, human genomic research can play a major role in precision public health research that impacts population health [92]. This can be achieved through increasing inclusion of underrepresented populations in genomics research to ensure that all of society shares in the economic and health benefits of precision public health investments [93].

\section{Conclusions}

While challenges lie ahead, the increased integration of human genomics research in precision public health is expected to provide opportunities for improving population health. To this end, there is a need to consider the most acceptable and effective way to scale advances in human genomic research to benefit populations by better targeting disease prevention, treatment, and control efforts. Transdisciplinary research that draws from precision medicine, genomics, and public health can continue to serve as a needed conduit towards the realization of the full range of opportunities in the emerging field of precision public health.

\section{Acknowledgements \\ Not applicable}

Authors' contributions

The authors read and approved the final manuscript.

Authors' information

Not applicable

Funding

Caitlin G. Allen was funded by F99 CA253576.

Availability of data and materials

Not applicable

\section{Declarations}

Ethics approval and consent to participate

Not applicable

\section{Consent for publication}

Not applicable

Competing interests

The authors declare that they have no competing interests.

\section{Author details}

'Division of Pharmaceutical Outcomes and Policy, University of North Carolina Eshelman School of Pharmacy, 301 Pharmacy Lane, Chapel Hill, NC 27599, USA. ${ }^{2}$ Department of Epidemiology and Institute of Public Health Genetics, University of Washington, 1959 NE Pacific Ave, Seattle, WA 98195, USA. ${ }^{3}$ Harvard Medical School, Harvard T.H. Chan School of Public Health, 
Brigham and Women's Hospital \&The Division of Population Sciences in Dana Farber Cancer Institute, 450 Brookline Ave, Boston, MA 02215-5450, USA. ${ }^{4}$ Department of Community Health Sciences, Cumming School of Medicine, University of Calgary, 3280 Hospital Drive NW, Calgary, AB T2N 4Z6, Canada. ${ }^{5}$ Cancer Epidemiology and Prevention Research, Sydney School of Public Health, Faculty of Medicine and Health, The University of Sydney, 119-143 Missenden Road, Camperdown, NSW 2050, Australia. ${ }^{6}$ Discipline of Genetic Counselling, The University of Technology Sydney, 100 Broadway, Ultimo, NSW 2008, Australia. ${ }^{7}$ Department of Behavioral Social and Health Education Sciences, Rollins School of Public Health, Emory University, 1518 Clifton Road, Atlanta, GA 30322, USA

Received: 5 November 2020 Accepted: 17 May 2021 Published online: 01 June 2021

\section{References}

1. National Institutes of Health. What is precision medicine? https://ghr.nlm. nih.gov/primer/precisionmedicine/definition. Published 2015. Accessed May 17, 2021.

2. Chowkwanyun M, Bayer R, Galea S. "Precision" public health - between novelty and hype. N Engl J Med. 2018;379(15):1398-400. https://doi.org/10.1 056/NEJMp1806634.

3. Galea S, Abdalla SM. Precision medicine approaches and the health of populations: study design concerns and considerations. Perspect Biol Med. 2018;61(4):527-36. https://doi.org/10.1353/pbm.2018.0062.

4. Khoury MJ, Galea S. Will precision medicine improve population health? JAMA. 2016;316(13):1357-8. https://doi.org/10.1001/jama.2016.12260

5. Khoury MJ, Bowen MS, Clyne M, Dotson WD, Gwinn ML, Green RF, et al. From public health genomics to precision public health: a 20-year journey. Genetics Med. 2018;20(6):574-82. https://doi.org/10.1038/gim.2017.211.

6. Khoury MJ, lademarco MF, Riley WT. Precision public health for the era of precision medicine. Am J Prev Med. 2016;50(3):398-401. https://doi.org/10.1 016/j.amepre.2015.08.031

7. Olstad DL, McIntyre L. Reconceptualising precision public health. BMJ Open. 2019;9(9):e030279. https://doi.org/10.1136/bmjopen-2019-030279.

8. Wehby GL, Domingue BW, Wolinsky FD. Genetic risks for chronic conditions: implications for long-term wellbeing. J Gerontol A Biol Sci Med Sci. 2018; 73(4):477-83. https://doi.org/10.1093/gerona/glx154.

9. Centers for Disease Control and Prevention. Family health history and chronic disease. https://www.cdc.gov/genomics/famhistory/famhist_ chronic_disease.htm. Published 2020. Accessed May 17, 2021.

10. Allen $C_{G}$, Fohner $A E$, Landry L, Paul JL, Smith SG, Turbitt E, et al. Perspectives from early career investigators who are "staying in the game" of precision public health research. Am J Public Health. 2019;109(9):1186-7. https://doi.org/10.2105/AJPH.2019.305199.

11. Benson AB 3rd, Venook AP, Al-Hawary MM, et al. NCCN Guidelines Insights: Colon Cancer, Version 2.2018. J Natl Compr Cancer Netw. 2018;16(4):359-69. https://doi.org/10.6004/jnccn.2018.0021.

12. Landau YE, Lichter-Konecki U, Levy HL. Genomics in newborn screening. J Pediatr. 2014;164(1):14-9. https://doi.org/10.1016/j.jpeds.2013.07.028.

13. Evans DGR, Harkness EF, Brentnall AR, van Veen EM, Astley SM, Byers $H$, et al. Breast cancer pathology and stage are better predicted by risk stratification models that include mammographic density and common genetic variants. Breast Cancer Res Treat. 2019;176(1):141-8. https://doi.org/1 0.1007/s10549-019-05210-2.

14. Drolet BC, Lorenzi NM. Translational research: understanding the continuum from bench to bedside. Transl Res. 2011;157(1):1-5. https://doi.org/10.1016/j. trsl.2010.10.002.

15. Khoury M, Gwinn M, Yoon P, Dowling N, Moore C, Bradley L. The continuum of translation research in genomic medicine: how can we accelerate the appropriate integration of human genome discoveries into health care and disease prevention. Genetics Med. 2007;9(10):665-74. https://doi.org/10.1097/GIM.0b013e31815699d0.

16. Association of Schools and Programs of Public Health. Areas of Study. https://www.aspph.org/study/\#areas-of-study. Published 2020. Accessed May 17, 2021

17. Auton A, Brooks LD, Durbin RM, et al. A global reference for human genetic variation. Nature. 2015;526(7571):68-74. https://doi.org/10.1038/nature15393.

18. Genetic Analysis Workshop. https://www.gaworkshop.org/. Published 2020. Accessed May 17, 2021.
19. All Syndromes Known to Man Evaluator. https://ask2me.org/. Published 2020. Accessed May 17, 2021.

20. Narayan S, Liew Z, Bronstein JM, Ritz B. Occupational pesticide use and Parkinson's disease in the Parkinson Environment Gene (PEG) study. Environ Int. 2017;107:266-73. https://doi.org/10.1016/j.envint.2017.04.010.

21. Brown TP, Rumsby PC, Capleton AC, Rushton L, Levy LS. Pesticides and Parkinson's disease--is there a link? Environ Health Perspect. 2006;114(2): 156-64. https://doi.org/10.1289/ehp.8095.

22. Woodahl EL, Lesko LJ, Hopkins S, Robinson RF, Thummel KE, Burke W. Pharmacogenetic research in partnership with American Indian and Alaska Native communities. Pharmacogenomics. 2014;15(9):1235-41. https://doi. org/10.2217/pgs.14.91.

23. IGNITE. Implementation Guides. https://gmkb.org/implementation-guides/. Published 2020. Accessed May 17, 2021.

24. National Human Genome Research Institute. Ethical, legal and social implications research program. https://www.genome.gov/Funded-Programs Projects/ELSI-Research-Program-ethical-legal-social-implications. Published 2020. Accessed May 17, 2021

25. NCGENES2. https://www.med.unc.edu/genetics/berglab/research/ncgenes2/. Published 2020. Accessed May 17, 2021

26. Godard B, Marshall J, Laberge C. Community engagement in genetic research: results of the first public consultation for the Quebec CARTaGENE project. Commun Genetics. 2007;10(3):147-58. https://doi.org/10.1159/0001 01756.

27. Tremblay M, Rouleau G. Deep genealogical analysis of a large cohort of participants in the CARTaGENE project (Quebec, Canada). Ann Hum Bio 2017;44(4):357-65. https://doi.org/10.1080/03014460.2017.1300326.

28. Schadt EE, Linderman MD, Sorenson J, Lee L, Nolan GP. Computational solutions to large-scale data management and analysis. Nat Rev Genet. 2010;11(9):647-57. https://doi.org/10.1038/nrg2857.

29. Gref A, Merid SK, Gruzieva O, Ballereau S, Becker A, Bellander T, et al. Genome-wide interaction analysis of air pollution exposure and childhood asthma with functional follow-up. Am J Respir Crit Care Med. 2017;195(10): 1373-83. https://doi.org/10.1164/rccm.201605-10260C

30. Wray A, Olstad DL, Minaker LM. Smart prevention: a new approach to primary and secondary cancer prevention in smart and connected communities. Cities. 2018;79(79):53-69. https://doi.org/10.1016/j.cities.2018. 02.022 .

31. Kharazmi E, Chen T, Fallah M, Sundquist $K$, Sundquist J, Albin M, et al. Familial risk of pleural mesothelioma increased drastically in certain occupations: a nationwide prospective cohort study. Eur J Cancer. 2018;103: 1-6. https://doi.org/10.1016/j.ejca.2018.07.139.

32. Burgard SA, Lin KY. Bad jobs, bad health? How work and working conditions contribute to health disparities. Am Behav Sci. 2013;57(8). https:// doi.org/10.1177/0002764213487347.

33. Turnbull C, Sud A, Houlston RS. Cancer genetics, precision prevention and a call to action. Nat Genet. 2018;50(9):1212-8. https://doi.org/10.1038/s41588018-0202-0

34. Marcus PM, Pashayan N, Church TR, Doria-Rose VP, Gould MK, Hubbard RA, et al. Population-based precision cancer screening: a symposium on evidence, epidemiology, and next steps. Cancer Epidemiol Biomarkers Prev. 2016;25(11):1449-55. https://doi.org/10.1158/1055-9965.EPI-16-0555.

35. Khera AV, Chaffin M, Aragam KG, Haas ME, Roselli C, Choi SH, et al. Genome-wide polygenic scores for common diseases identify individuals with risk equivalent to monogenic mutations. Nat Genet. 2018;50(9):121924. https://doi.org/10.1038/s41588-018-0183-z.

36. Torkamani A, Wineinger NE, Topol EJ. The personal and clinical utility of polygenic risk scores. Nat Rev Genet. 2018;19(9):581-90. https://doi.org/10.1 038/s41576-018-0018-x.

37. Smit AK, Newson AJ, Morton RL, Kimlin M, Keogh L, Law MH, et al. The melanoma genomics managing your risk study: a protocol for a randomized controlled trial evaluating the impact of personal genomic risk information on skin cancer prevention behaviors. Contemp Clin Trials. 2018; 70:106-16. https://doi.org/10.1016/j.cct.2018.05.014.

38. Glanz K, Schoenfeld ER, Steffen A. A randomized trial of tailored skin cancer prevention messages for adults: Project SCAPE. Am J Public Health. 2010; 100(4):735-41. https://doi.org/10.2105/AJPH.2008.155705

39. Pashayan N, Morris S, Gilbert FJ, Pharoah PDP. Cost-effectiveness and benefit-to-harm ratio of risk-stratified screening for breast cancer: a life-table model. JAMA Oncol. 2018:4(11):1504-10. https://doi.org/10.1001/jama oncol.2018.1901. 
40. Callender T, Emberton M, Morris S, Eeles R, Kote-Jarai Z, Pharoah PDP, et al Polygenic risk-tailored screening for prostate cancer: a benefit-harm and cost-effectiveness modelling study. PLoS Med. 2019;16(12):e1002998. https:// doi.org/10.1371/journal.pmed.1002998.

41. Subramanian S, Bobashev G, Morris RJ, Hoover S. Personalized medicine for prevention: can risk stratified screening decrease colorectal cancer mortality at an acceptable cost? Cancer Causes Control. 2017;28(4):299-308. https:// doi.org/10.1007/s10552-017-0864-4.

42. Landi MT, Bishop DT, MacGregor S, et al. Genome-wide association metaanalyses combining multiple risk phenotypes provide insights into the genetic architecture of cutaneous melanoma susceptibility. Nat Genet. 2020; 52(5):494-504. https://doi.org/10.1038/s41588-020-0611-8.

43. Mavaddat N, Michailidou K, Dennis J, Lush M, Fachal L, Lee A, et al. Polygenic risk scores for prediction of breast cancer and breast cancer subtypes. Am J Hum Genet. 2019;104(1):21-34. https://doi.org/10.1016/j.a jhg.2018.11.002.

44. Fahed AC, Wang M, Homburger JR, Patel AP, Bick AG, Neben CL, et al. Polygenic background modifies penetrance of monogenic variants for tier 1 genomic conditions. Nat Commun. 2020;11(1):3635. https://doi.org/10.1038/ s41467-020-17374-3.

45. Lee A, Mavaddat N, Wilcox AN, Cunningham AP, Carver T, Hartley S, et al. BOADICEA: a comprehensive breast cancer risk prediction model incorporating genetic and nongenetic risk factors. Genetics Med. 2019;21(8): 1708-18. https://doi.org/10.1038/s41436-018-0406-9.

46. Cust AE, Drummond M, Kanetsky PA, Goldstein AM, Barrett JH, MacGregor S, et al. Assessing the incremental contribution of common genomic variants to melanoma risk prediction in two population-based studies. J Invest Dermatol. 2018;138(12):2617-24. https://doi.org/10.1016/ j.jid.2018.05.023

47. Alegría-Torres JA, Baccarelli A, Bollati V. Epigenetics and lifestyle. Epigenomics. 2011;3(3):267-77. https://doi.org/10.2217/epi.11.22.

48. Messerlian C, Martinez RM, Hauser R, Baccarelli AA. 'Omics' and endocrinedisrupting chemicals - new paths forward. Nat Rev Endocrinol. 2017;13(12): 740-8. https://doi.org/10.1038/nrendo.2017.81.

49. Au NT, Ryman $T$, Rettie $A E$, et al. Dietary vitamin $K$ and association with hepatic vitamin $\mathrm{K}$ status in a Yup'ik study population from Southwestern Alaska. Mol Nutr Food Res. 2018;62(3). https://doi.org/10.1 002/mnfr.201700746.

50. Fohner AE, Wang Z, Yracheta J, O'Brien DM, Hopkins SE, Black J, et al. Genetics, diet, and season are associated with serum 25hydroxycholecalciferol concentration in a Yup'ik study population from Southwestern Alaska. J Nutr. 2016;146(2):318-25. https://doi.org/10.3945/ jn.115.223388.

51. Bhatraju PK, Mukherjee P, Robinson-Cohen C, O'Keefe GE, Frank AJ, Christie $J \mathrm{D}$, et al. Acute kidney injury subphenotypes based on creatinine trajectory identifies patients at increased risk of death. Crit Care. 2016;20(1):372. https://doi.org/10.1186/s13054-016-1546-4.

52. Yanes T, Young MA, Meiser B, James PA. Clinical applications of polygenic breast cancer risk: a critical review and perspectives of an emerging field. Breast Cancer Res. 2020;22(1):21. https://doi.org/10.1186/s13058-020-01260-3.

53. Fohner AE, Volk KG, Woodahl EL. Democratizing precision medicine through community engagement. Clin Pharmacol Ther. 2019;106(3):488-90. https:// doi.org/10.1002/cpt.1508.

54. Roberts MC, Kennedy AE, Chambers DA, Khoury MJ. The current state of implementation science in genomic medicine: opportunities for improvement. Genetics Med. 2017;19(8):858-63. https://doi.org/10.1038/ gim.2016.210

55. Roberts MC, Mensah GA, Khoury MJ. Leveraging implementation science to address health disparities in genomic medicine: examples from the field. Ethn Dis. 2019;29(Suppl 1):187-92. https://doi.org/10.1 8865/ed.29.S1.187

56. Nooraie RY, Kwan BM, Chohn E, AuYoung M. Advancing health equity through CTSA programs: Opportunities for interaction between health equity, dissemination and implementation, and translational science. J Clin Transl Sci. 2020;4(3):168-75. https://doi.org/10.1017/cts.2020.10.

57. Department of Health and Human Services. Dissemination and implementation research in health (R01 Clinical Trial Optional). https://gra nts.nih.gov/grants/guide/pa-files/PAR-19-274.html. Published 2020. Accessed May 17, 2021.

58. Implementing Genomics in Practice. Implementation Guides. https://gmkb. org/implementation-guides/. Published 2020. Accessed May 17, 2021.
59. Clinical Pharmacogenetics Implementation Consotrium. https://cpicpgx.org/. Published 2020. Accessed May 17, 2021.

60. Stark Z, Boughtwood T, Phillips P, Christodoulou J, Hansen DP, Braithwaite J, et al. Australian Genomics: a federated model for integrating genomics into healthcare. Am J Hum Genet. 2019;105(1):7-14. https://doi.org/10.1016/j.a jhg.2019.06.003.

61. Lunke S, Eggers S, Wilson M, et al. Feasibility of ultra-rapid exome sequencing in critically ill infants and children with suspected monogenic conditions in the australian public health care system. JAMA. 2020;323(24): 2503-11. https://doi.org/10.1001/jama.2020.7671.

62. World Health Organization. A conceptual framework for action on the social determinants of health. https://www.who.int/sdhconference/resources/ ConceptualframeworkforactiononSDH_eng.pdf Published 2010. Accessed May 17, 2021.

63. McBride CM, Bowen D, Brody LC, et al. Future health applications of genomics: priorities for communication, behavioral, and social sciences research. Am J Prev Med. 2010;38(5):556-65. https://doi.org/10.1016/j.a mepre.2010.01.027.

64. McBride CM, Graves KD, Kaphingst KA, et al. Behavioral and social scientists' reflections on genomics: a systematic evaluation within the Society of Behavioral Medicine. Trans/ Behav Med. 2019;9(6):1012-9. https://doi.org/10.1 093/tbm/ibz044

65. Allen CG, Peterson S, Khoury MJ, Brody LC, McBride CM. A scoping review of social and behavioral science research to translate genomic discoveries into population health impact. Transl Behav Med. 2021;11(4):901-11. https:// doi.org/10.1093/tbm/ibaa076.

66. Turbitt $\mathrm{E}$, Biesecker BB. A primer in genomics for social and behavioral investigators. Transl Behav Med. 2020;10(2):451-6. https://doi.org/10.1093/ tbm/ibz018.

67. Griesemer I, Staley BS, Lightfoot AF, Bain L, Byrd D, Conway C, et al. Engaging community stakeholders in research on best practices for clinical genomic sequencing. Personalized Med. 2020;17(6):435-44. https://doi.org/1 0.2217/pme-2020-0074.

68. Bowen DJ, Hay J, Meischke H, Mayer JA, Harris-Wai J, Burke W. Randomized trial of a web-based survivor intervention on melanoma prevention behaviors of first-degree relatives. Cancer Causes Control. 2019;30(3):225-33. https://doi.org/10.1007/s10552-018-1096-y.

69. Rahm AK, Cragun D, Hunter JE, Epstein MM, Lowery J, Lu CY, et al. Implementing universal Lynch syndrome screening (IMPULSS): protocol for a multi-site study to identify strategies to implement, adapt, and sustain genomic medicine programs in different organizational contexts. BMC Health Serv Res. 2018;18(1):824. https://doi.org/10.1186/s12913-01 8-3636-2.

70. Scherr CL, Bomboka L, Nelson A, Pal T, Vadaparampil ST. Tracking the dissemination of a culturally targeted brochure to promote awareness of hereditary breast and ovarian cancer among Black women. Patient Educ Couns. 2017;100(5):805-11. https://doi.org/10.1016/j.pec.2016.10.026.

71. Pasick RJ, Joseph G, Stewart S, Kaplan C, Lee R, Luce J, et al. Effective referral of low-income women at risk for hereditary breast and ovarian cancer to genetic counseling: a randomized delayed intervention control trial. Am J Public Health. 2016;106(10):1842-8. https://doi.org/1 0.2105/AJPH.2016.303312.

72. Fuller KC, McCarty C, Seaborn C, Gravlee CC, Mulligan CJ. ACE gene haplotypes and social networks: Using a biocultural framework to investigate blood pressure variation in African Americans. PLoS One. 2018; 13(9):e0204127. https://doi.org/10.1371/journal.pone.0204127.

73. Hamid JS, Hu P, Roslin NM, Ling V, Greenwood CM, Beyene J. Data integration in genetics and genomics: methods and challenges. Hum Genomics Proteomics. 2009. https://doi.org/10.4061/2009/869093.

74. Prosperi M, Min JS, Bian J, Modave F. Big data hurdles in precision medicine and precision public health. BMC Med Inform Decis Mak. 2018;18(1):139. https://doi.org/10.1186/s12911-018-0719-2.

75. Luke V Rasmussen, Maureen E Smith, Federico Almaraz, Stephen D Persell, Laura J Rasmussen-Torvik, Jennifer A Pacheco, Rex L Chisholm, Carl Christensen, Timothy M Herr, Firas H Wehbe, Justin B Starren, An ancillary genomics system to support the return of pharmacogenomic results, J Am Med Inform Assoc. 2019;26(4):306-10. https://doi.org/10.1 093/jamia/ocy187.

76. Byrd AL, Manuck SB. MAOA, childhood maltreatment, and antisocial behavior: meta-analysis of a gene-environment interaction. Biol Psychiatry. 2014;75(1):9-17. https://doi.org/10.1016/j.biopsych.2013.05.004. 
77. Centers of Excellence in ELSI Research (CEER). https://www.genome.gov/ Funded-Programs-Projects/ELSI-Research-Program/Centers-of-Excellence. Published 2020. Accessed May 17, 2021.

78. Comission USEEO. The Genetic Information Nondiscrimination Act of 2008 https://www.eeoc.gov/statutes/genetic-information-nondiscrimination-act-2 008. Published 2008. Accessed May 17, 2021.

79. Roberts MC, Dotson WD, DeVore CS, et al. Delivery of cascade screening for hereditary conditions: a scoping review of the literature. Health Aff (Millwood). 2018;37(5):801-8. https://doi.org/10.1377/hlthaff.2017.1630.

80. Roundtable on Translating Genomic-Based Research for $\mathrm{H}$, Board on Health Sciences P, Institute of M. The National Academies Collection: reports funded by National Institutes of Health. In: Genomics-Enabled Learning Health Care Systems: Gathering and Using Genomic Information to Improve Patient Care and Research: Workshop Summary. Washington (DC): National Academies Press (US) Copyright 2015 by the National Academy of Sciences. All rights reserved.; 2015

81. Overby CL, Tarczy-Hornoch P, Hoath JI, Kalet IJ, Veenstra DL. Feasibility of incorporating genomic knowledge into electronic medical records for pharmacogenomic clinical decision support. BMC Bioinformatics. 2010;11 Suppl 9(Suppl 9):S10

82. Nau C, Ellis H, Huang H, Schwartz BS, Hirsch A, Bailey-Davis L, et al. Exploring the forest instead of the trees: An innovative method for defining obesogenic and obesoprotective environments. Health Place. 2015;35:13646. https://doi.org/10.1016/j.healthplace.2015.08.002.

83. Roberts MC. Implementation challenges for risk-stratified screening in the era of precision medicine. JAMA Oncol. 2018;4(11):1484-5. https://doi.org/1 0.1001/jamaoncol.2018.1940.

84. Hall M, Olopade Ol. Confronting genetic testing disparities: knowledge is power. JAMA. 2005;293(14):1783-5. https://doi.org/10.1001/jama.293.14.1783.

85. Oloparde Ol. Genetics in clinical cancer care: a promise unfulfilled among minority populations. Cancer Epidemiol Biomarkers Prev. 2004;13(11 Pt 1): $1683-6$.

86. Evans MK, Rosenbaum L, Malina D, Morrissey S, Rubin EJ. Diagnosing and treating systemic racism. N Engl J Med. 2020;383(3):274-6. https://doi.org/1 0.1056/NEJMe2021693.

87. Centers for Disease Control and Prevention. Tier 1 genomics applications and their importance to public health. https://www.cdc.gov/genomics/ implementation/toolkit/tier1.htm. Published 2014. Accessed May 17, 2021.

88. Abul-Husn NS, Soper ER, Braganza GT, Rodriguez JE, Zeid N, Cullina S, et al. Implementing genomic screening in diverse populations. Genome Med. 2021;13(1):17. https://doi.org/10.1186/s13073-021-00832-y.

89. National Instututes of Health. All of US Research Program. https://allofus.nih. gov/. Published 2018. Accessed May 17, 2021.

90. Jacobs EA, Rolle I, Ferrans CE, Whitaker EE, Warnecke RB. Understanding African Americans' views of the trustworthiness of physicians. J Gen Intern Med. 2006;21(6):642-7. https://doi.org/10.1111/j.1525-1497.2006.00485.x.

91. Allen CG, Fohner AE, Landry L, Paul J, Smith SG, Turbitt E, et al. Early career investigators and precision public health. Lancet. 2019;394(10196):382-3. https://doi.org/10.1016/S0140-6736(19)30498-2.

92. Rose G. Sick individuals and sick populations. Int J Epidemiol. 1985;14(1):32-8. https://doi.org/10.1093/ije/14.1.32.

93. Fox K. The illusion of inclusion - the "all of us" research program and indigenous peoples' DNA. N Engl J Med. 2020;383(5):411-3. https://doi.org/1 0.1056/NEJMp1915987.

\section{Publisher's Note}

Springer Nature remains neutral with regard to jurisdictional claims in published maps and institutional affiliations. 